\title{
Metodologias Ativas no Ensino de Ciências e Biologia: compreendendo as produções da última década
}

\author{
Active Methodologies in Science and Biology Education: understanding the \\ last decade productions

\section{Metodologías activas en la enseñanza de la ciencia y la biología: comprensión de las producciones de la última década}

\author{
Leoni Ventura Costa (leoni.ventura@ufpr.br) \\ Universidade Federal do Paraná. \\ Tiago Venturi (tiago.venturi@ufpr.br) \\ Universidade Federal do Paraná.
}

\begin{abstract}
Resumo: A formação para aprendizagem autônoma, pensamento crítico de investigativo são fundamentais para atender as demandas sociais na sociedade do conhecimento. De modo a contribuir com estas necessidades formativas, por meio de uma revisão sistemática de literatura, este estudo objetiva compreender como metodologias ativas estão sendo abordadas nas pesquisas acadêmicas no ensino de ciências e biologia. Verificou-se que, apesar da variedade de metodologias ativas existentes, poucas são utilizadas e introduzidas na prática escolar. Além disso, foi possível destacar diversos benefícios da utilização destas para o processo de ensino aprendizagem. Os resultados indicam que, existe uma demanda latente na formação de professores para a utilização de metodologias ativas, assim como são necessário novos estudos que se dediquem a investigar e discutir possibilidades e abordagens para a inserção das metodologias ativas no contexto escolar e nas aulas de Ciências e Biologia.
\end{abstract}

Palavras-chave: metodologias ativas; ensino de ciências e biologia; ensino e aprendizagem.

\begin{abstract}
Training for autonomous learning, critical investigative thinking are essential to meet the social demands in the knowledge society. In order to contribute to these training needs, through a systematic literature review, this study aims to understand how active methodologies are being addressed in academic research in Science and Biology teaching. It was found that, despite the variety of existing active methodologies, few are used and introduced in school practice. In addition, it was possible to highlight several benefits of using these for the teaching-learning process. The results indicate that there is a latent demand in the training of teachers for the use of active methodologies, as well as new studies that are dedicated to investigate and discuss possibilities and approaches for the insertion of active methodologies in the school context and in Science and Biology classes.
\end{abstract}

Keywords: active methodologies; science and biology teaching; teaching and learning.

Recebido em: 24/05/2021

Aceite em: 22/09/2021 
Resumen: La formación para el aprendizaje autónomo, el pensamiento crítico investigador son fundamentales para atender las demandas sociales de la sociedad del conocimiento. Con el fin de contribuir a estas necesidades de formación, a través de una revisión sistemática de la literatura, este estudio tiene como objetivo comprender cómo se están abordando las metodologías activas en la investigación académica en la enseñanza de la ciencia y la biología. Se encontró que, apesar de la variedad de metodologías activas existentes, pocas se utilizan e introducen en la práctica escolar. Además, fue posible destacar varios beneficios de utilizar estos para el proceso de enseñanza-aprendizaje. Los resultados indican que existe una demanda latente en la formación de docentes para el uso de metodologías activas, así como nuevos estudios que se dediquen a investigar y discutir posibilidades y enfoques para la inserción de metodologías activas en el contexto escolar y en las clases de Ciencias y Biología.

Palabras-clave: metodologías activas; enseñanza de la ciencia y la biología; enseñando y aprendiendo.

\section{INTRODUÇÃO}

A atual sociedade da informação, do conhecimento, tecnológica e conectada, demanda o desenvolvimento de novas habilidades e competências à formação para a cidadania, tais como: comunicação digital e midiática, aprendizagem autônoma, ética e responsabilidade, trabalho em equipe e flexibilidade, pensamento crítico, criatividade e capacidade de resolução de problemas, domínio de tecnologias digitais, gestão do conhecimento, dentre outras (BATES, 2017). Como afirmou o Professor António Nóvoa, em entrevista à Boto (2018, p.18), a "revolução digital coloca-nos perante novas maneiras de pensar, de conhecer, de comunicar e, sobretudo, de aprender". Para tanto, à escola e aos professores foram impostos novos desafios: construir espaços e estratégias de ensino e aprendizagem inovadoras, dinâmicas, vivas e ativas. Neste contexto, avançam discussões, implementações e estratégias denominadas de metodologias ativas.

No momento atual, em meio à pandemia de Covid-19, enquanto circulam incontáveis informações científicas e desinformações negacionistas e anticientíficas, notamos a importância do desenvolvimento destas habilidades e competências por meio do Ensino de Ciências (EC). É consenso que as Ciências da Natureza estão intimamente ligadas às questões sociais, científicas e tecnológicas, relação evidenciada pela crise sanitária, econômica, política e científica vivenciada no presente momento. Diante deste cenário, reconhecemos que o EC requer abordagens didático-pedagógicas que integrem conhecimentos científicos, tecnologias

Recebido em: 24/05/2021

Aceite em: 22/09/2021 
digitais da informação e comunicação (TDIC) e questões que permeiam o dia a dia dos alunos, objetivando a contextualização na construção de conhecimentos. Entretanto, a literatura aponta diversos desafios para que esta integração se torne real no contexto escolar brasileiro, dentre os quais destacamos o ensino tradicional, caracterizado por adotar estratégias informativas, bancárias, unidirecionais e centradas no professor (MATTAR, 2017).

Ao analisar e discutir as abordagens adotadas nas disciplinas de Ciências e Biologia, Krasilchik e Marandino (2004) afirmam que, via de regra, os conteúdos são abordados de forma expositiva e teórica, o que impossibilita o contato contextualizado entre o objeto de estudo, conhecimentos científicos e a realidade dos alunos. As autoras destacam que as dificuldades são resultantes de inúmeros fatores e evidenciam as deficiências na formação docente, tanto inicial quanto continuada, na qual podemos incluir a inexistência de espaços para formação em abordagens teórico-metodológicas inovadoras e interdisciplinares.

Em contraposição a esse formato tradicional, surgem estratégias educacionais mediadas por tecnologias, como o ensino híbrido, educação maker, abordagens ativas, dentre outras expressões utilizadas para designar as metodologias ativas. As metodologias ativas têm como premissa a articulação da teoria com a prática, a realidade e a contextualização, com o objetivo de tornar o aluno protagonista do seu desenvolvimento e da construção do seu conhecimento (BERBEL, 2011).

Neste sentido, consideramos que não é mais adequado ao Ensino de Ciências e Biologia o repasse de informações ou a exposição de uma lista de conteúdos, com nomes complexos que precisam ser memorizados. Ao Ensino de Ciências e Biologia cabe criar espaços para a construção de conhecimentos que permitam aos alunos compreender o mundo em que vivem e atuar neste como cidadãos da sociedade do conhecimento. Para refletir acerca dos limites e possibilidades de criação de espaços inovadores de ensino, precisamos compreender: como a área de pesquisa em Ensino de Ciências e Biologia vem tratando e analisando as possibilidades das metodologias ativas? Quais as considerações acerca da utilização de metodologias ativas como alternativa ao ensino tradicional? Levando em consideração que as metodologias ativas podem ser importantes aliadas do Ensino de Ciências e Biologia, neste estudo temos como objetivo compreender como estas metodologias vêm sendo abordadas nas pesquisas acadêmicas na área do Ensino de Ciências e Biologia, por meio de uma revisão sistemática de artigos publicados nos principais periódicos e eventos científicos deste campo de estudos.

Recebido em: 24/05/2021

Aceite em: 22/09/202 1 
Acreditamos que este estudo possa contribuir com a compreensão dos desafios e possibilidades do uso das metodologias ativas, refletindo sobre os caminhos necessário à educação brasileira e à formação de professores, de modo a romper com o paradigma dominante.

\section{METODOLOGIAS ATIVAS: BREVE FUNDAMENTAÇÃO}

Os processos de ensino e aprendizagem no Brasil ainda são, em sua grande maioria, realizados de forma tradicional, onde o aluno é considerado um ser passivo, à espera de receber conhecimentos e informações do professor. Para Borges e Alencar (2014), é necessário que o professor esteja pronto para repensar a construção do conhecimento, de modo que a mediação e interação sejam fatores imprescindíveis para a aprendizagem.

Em nossas experiências, enquanto alunos e docentes da Educação Básica, percebemos que o Ensino de Ciências e Biologia não foge dos modelos de ensino tradicionais, onde conteúdos são abordados de forma expositiva, utilizando-se de termos científicos e linguagem técnica, que criam barreiras e lacunas para a aprendizagem do estudante, muitas vezes, resultando apenas em uma memorização descontextualizada. No entanto, reconhecemos que as disciplinas de Ciências e Biologia têm potencial para proporcionar um processo de alfabetização científica, de modo a permitir aos estudantes compreender as relações entre os conhecimentos científicos, a sociedade e sua utilização no cotidiano e, como consequência, desenvolver uma postura crítica e autônoma, bem como, estimular a correlação destes conhecimentos com os de outras disciplinas (KRASILCHIK; MARANDINO, 2004). Neste sentido, Furlani e Oliveira (2018) afirmam que a utilização das metodologias ativas pode contribuir com a integração de conteúdos, evitando assim, que o aluno visualize os conteúdos de Ciências ou Biologia como um compilado de termos complexos a serem decorados.

Autores como Borges e Alencar (2014) e Moran (2017) afirmam que as metodologias ativas são estratégias didáticas que promovem a participação efetiva dos alunos nos processos de ensino e aprendizagem, de forma flexível, interligada, interativa, autônoma e híbrida, onde as tecnologias são imprescindíveis para que o professor possa assumir o papel de mediador da construção de conhecimentos. Segundo Berbel (2011), as metodologias ativas utilizam-se de experiências reais ou simuladas, visando obter sucesso ao solucionar problemas provenientes das atividades essenciais da prática social, em diferentes contextos. Mattar (2017) afirma que 
são inúmeras as metodologias ativas, mas as que mais se destacam são: Aprendizagem Baseada em Problemas (ABP), Peer Instruction (Instrução por Pares), Ensino Híbrido, Ensino por Investigação, dentre outras.

A Aprendizagem Baseada em Problemas tem como base a utilização de problemas do cotidiano para estimular o desenvolvimento conceitual, procedimental e atitudinal do discente (BOROCHOVICIUS; TORTELLA, 2014). Esta metodologia favorece a busca por respostas ou soluções para problemas, o que pode resultar na contextualização do ensino e no desenvolvimento da autonomia dos alunos, uma vez que os problemas utilizados são facilmente encontrados no cotidiano dos alunos.

A metodologia da Instrução por Pares é pautada na interação entre colegas, o que proporciona troca de conhecimentos, diferentes ideias e informações. Segundo Moura, Santos e José (2015), a colaboração entre os colegas em sala de aula pode resultar positivamente na aprendizagem, pois durante as discussões os colegas ajudam uns aos outros a construírem e consolidarem suas compreensões sobre os assuntos estudados.

Já o ensino híbrido tem como premissa a utilização de tecnologias nos processos de ensino e aprendizagem. Por meio de tecnologias é possível ampliar o conhecimento do estudante, uma vez que há grande quantidade de informações disponíveis na internet. De acordo com Moran (2017) as tecnologias ampliam as possibilidades de pesquisa online e ajudam a difundir projetos e aprendizagens que podem romper as barreiras no ambiente escolar.

Por fim, ainda consideramos importante destacar o ensino por investigação, que é responsável por inserir o aluno no universo científico, visto que têm como princípios seguir as metodologias científicas para a construção de conhecimentos escolar. Como consequência, Zômpero e Laburú (2011) afirmam que a investigação promove o desenvolvimento de atividades cognitivas, decorrentes do levantamento de hipóteses, anotações, observações, coleta de dados, análise de dados e desenvolvimento da capacidade de argumentação.

No entanto, para que estas metodologias contribuam com o processo de alfabetização científica no Ensino de Ciências e Biologia é necessário que tenhamos domínio destas metodologias e conhecimento de seus limites e possibilidades no contexto escolar. Diante do exposto, na sequência apresentamos a metodologia de investigação utilizada a fim de 
compreender como o Ensino de Ciências e Biologia vem utilizando, percebendo e avaliando as metodologias ativas em seu campo de pesquisas e práticas.

\section{CAMINHOS DA PESQUISA}

A investigação caracteriza-se como pesquisa bibliográfica, também denominada de revisão sistematizada, pois utilizou-se de artigos já publicados em periódicos ou atas de eventos. Para Gil (2002), a pesquisa bibliográfica é desenvolvida com base em material já elaborado, constituída principalmente de livros e artigos científicos. Este estudo apresenta ainda uma abordagem qualitativa, visto que buscamos construir uma compreensão sobre como os estudos que vêm sendo realizados acerca metodologias ativas. O que condiz com Richardson (1999), quando afirma que uma abordagem qualitativa pode contribuir com a análise e interpretação de diversas variáveis, bem como permitir uma melhor compreensão e classificação de processos dinâmicos vivenciados por grupos sociais.

Para a realização da pesquisa utilizamos artigos de natureza empírica (que desenvolveram e analisaram metodologias ativas) e de natureza teórica (revisões bibliográficas e ensaios teóricos). Para a seleção dos artigos foram utilizadas as atas do Encontro Nacional de Pesquisa em Educação em Ciências (ENPEC), evento mais importante da área de Educação em Ciências no Brasil e que tem o objetivo de "promover a interação $e$ fomentar estudos e pesquisas realizados por profissionais das áreas do Ensino de Física, Química, Biologia, Geociências, Ambiente, Saúde e áreas afins"1. O encontro é realizado bianualmente e todos os trabalhos ficam disponíveis, de forma gratuita e online, no site da Associação Brasileira de Pesquisa em Educação em Ciências (ABRAPEC). No site é possível buscar trabalhos, por título, autor, área e palavras-chave. Para a busca dos artigos foram utilizadas as palavras-chave: "metodologias ativas" e "metodologia ativa" em resumos e títulos.

Também foram alvo da revisão seis revistas certificadas com Qualis/CAPES “A” na área de Ensino e caracterizadas como revistas cujo foco de publicações é pesquisa em Ensino de Ciências: Revista Alexandria, Ciências e Educação, Ensaio - Pesquisa em Educação em Ciências, Investigação em Ensino de Ciências, Revista Brasileira de Pesquisa em Educação em Ciências e Revista Experiência no Ensino de Ciências.

${ }^{1}$ Extraído da página da ABRAPEC, disponível em http://abrapecnet.org.br/

Recebido em: 24/05/2021

Aceite em: 22/09/2021 
Os critérios de inclusão foram: i) estudos publicados nos últimos sete anos no ENPEC, compreendendo os anos de 2013, 2015, 2017, 2019 e estudos publicados nos últimos dez anos nos periódicos; ii) estudos publicados em língua portuguesa; iii) texto integral, disponível em formato eletrônico e gratuito; iv) estudos realizados em contexto educacional/formativo; v) estudos que se enquadram na área de Ensino de Ciências (ciências, física, química, biologia), e; v) revistas certificadas com Qualis/CAPES “A” na área de Ensino (quadriênio 2013-2016). O universo de análise compreendeu 7470 trabalhos publicados nos repositórios consultados, dos quais foram selecionados 169 artigos para compor o corpus de análise, conforme tabela 01.

Tabela 01: tabela com a quantidade total de artigos encontrados em cada revista e evento e artigos selecionados para o estudo.

\begin{tabular}{|l|l|l|}
\hline \multicolumn{1}{|c|}{ Repositório Pesquisado } & Quantidade total de artigos & Artigos selecionados \\
\hline ENPEC (2013 a 2019) & 4975 & 36 \\
\hline Revista Alexandria & 281 & 7 \\
\hline Revista Ciências e Educação & 625 & 7 \\
\hline Revista Contexto e Educação & 192 & 4 \\
\hline Ensaio Pesquisa em Educação & 370 & 4 \\
\hline Revista Investigação em Ensino de Ciências & 385 & 17 \\
\hline Revista Brasileira de pesquisa de Educação em Ciências & 358 & 24 \\
\hline Revista Experiência no Ensino de Ciências & 642 & 70 \\
\hline Total & $\mathbf{7 4 7 0}$ & $\mathbf{1 6 9}$ \\
\hline
\end{tabular}

Fonte: elaborado pelos autores.

Em seguida, todos os artigos selecionados foram lidos e analisados conforme critérios abaixo, inspirados em Paiva et al. (2016):

a) Cenário de intervenção: tem o objetivo de identificar para quais níveis de educação os estudos estão voltados, ou quais os cenários de uso das metodologias ativas tais como ensino fundamental, ensino médio, ensino superior, ensino tecnológico, dentre outros.

b) Tipos de pesquisa: tem o objetivo de classificar o tipo de pesquisa indicada na metodologia dos artigos encontrados, levando em conta sua natureza empírica ou teórica, tais como: pesquisas empíricas com intervenções em cenários educacionais; revisões de literatura; pesquisas documentais, análises curriculares ou de livros didáticos.

c) Estratégias metodológicas: este critério tem por objetivo identificar as metodologias utilizadas nos estudos selecionados.

d) Benefícios da utilização de metodologias ativas no ensino: tem o objetivo de constatar quais as melhorias/benefícios alcançados no ensino, com a utilização das metodologias ativas

Recebido em: 24/05/2021

Aceite em: 22/09/2021 
e) Áreas disciplinares dos trabalhos: tem o propósito de identificar em quais as áreas disciplinares as metodologias foram desenvolvidas como estratégias de ensino.

f) Metodologias Ativas para a formação de professores: tem objetivo de identificar os limites e potencialidades das metodologias ativas na formação de professores.

g) Análise e avaliação de metodologias ativas: estudos que buscam construir estratégias, ferramentas e/ou categorias de análise e avaliação de metodologias ativas desenvolvidas em contexto educacional.

Na sequência apresentamos e discutimos os resultados encontrados na investigação à luz da literatura.

\section{RESULTADOS E DISCUSSÕES}

Inicialmente é importante analisarmos a evolução das publicações acerca das metodologias ativas, tanto nos ENPECs quanto nos periódicos da área de Ensino de Ciências. Nos últimos dez anos, podemos observar um certo crescimento a partir de 2015 e um crescimento bastante evidente nas publicações a partir de 2017, atingindo um ápice em 2018 nos periódicos e em 2019 no ENPEC, conforme gráfico da Figura 1.

Figura 1- evolução das publicações acerca das metodologias ativas nos últimos 10 anos.

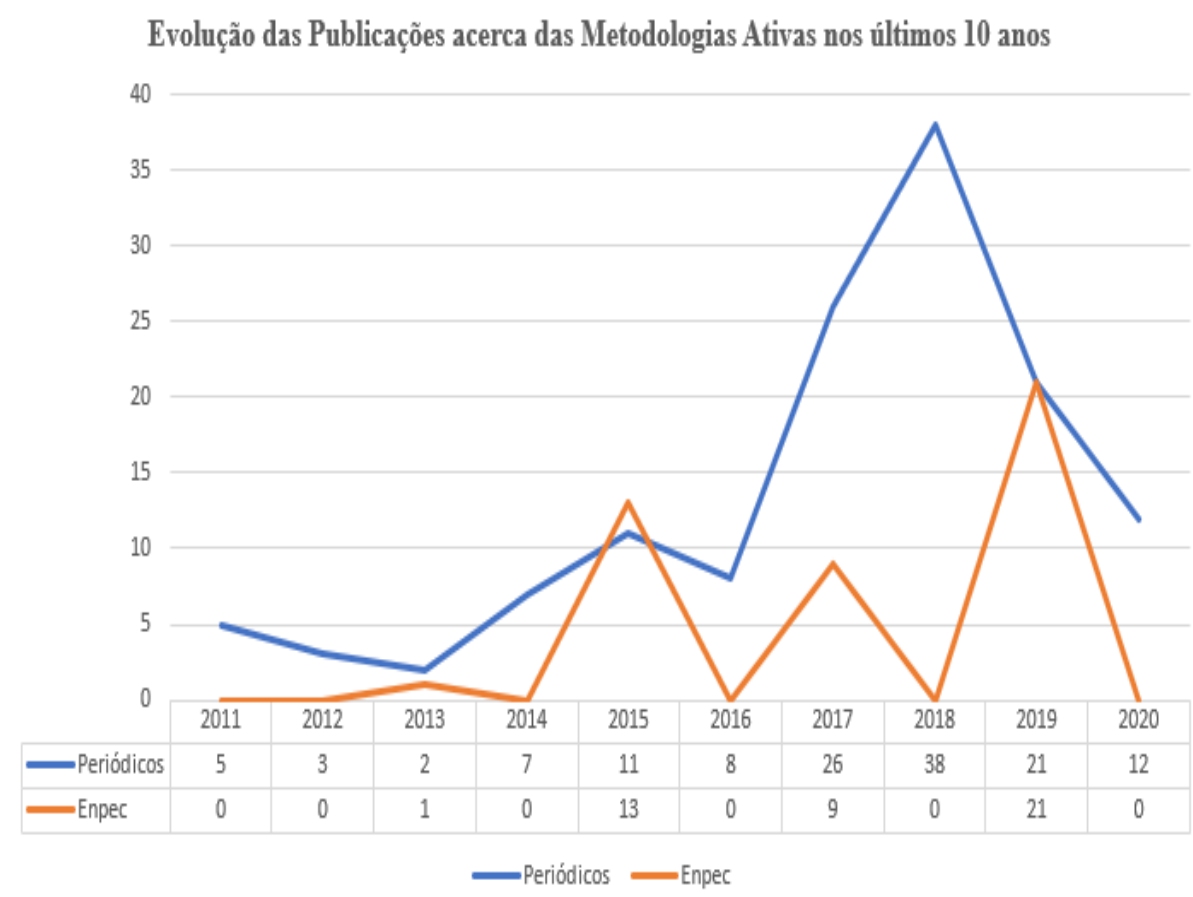

Recebido em: 24/05/2021

Aceite em: 22/09/2021 
Fonte: elaborado pelos autores.

Tal fato pode encontrar explicações nos estudos de Mota e Rosa (2018), que discutem que o avanço das metodologias ativas na educação está diretamente conectado às novas compreensões e descobertas da área da psicologia cognitiva e da neurociência. Para as autoras as metodologias ativas estão vinculadas ao sócio construtivismo e à metacognição, que tornam o estudante protagonista e responsável pela análise, regulação e avaliação dos mecanismos promotores da sua aprendizagem. Assim, salientam a importância da reflexão, de um papel mais ativo e da autonomia nos processos de aprendizagem. São compreensões reafirmadas pela neurociência que, segundo Consenza e Guerra (2011), vem demonstrando que a aprendizagem é consequência de redes de interações complexas entre os neurônios, capazes de aumentar a sobrevivência e gerar novas redes neurais, modificando estruturas cerebrais do indivíduo aprendente. Além disso, estes estudos demonstram que o cérebro precisa de tempo para assimilar e que a aprendizagem contextualizada, ativa e vivenciada em situações do cotidiano trazem melhores resultados (CONSENZA; GUERRA, 2011). No entanto, estudos mais complexos em neurociências e com resultados mais evidentes são recentes, aparecendo em publicações nacionais a partir de 2010, de acordo com os estudos de Nunes, Coutinho e Moraes (2015).

Assim, podemos inferir que a partir deste período a área de Ensino de Ciências passou a interessar-se, ainda que de maneira tímida, pelas metodologias ativas. Assim, passou-se a levar em conta estudos emergentes da neurociência e da psicologia cognitiva que têm demonstrado que a aprendizagem é promovida e mais significativa quando adotam-se estratégias mais ativas, em que o estudante se encontra em ação, participa de debates, discute e ensina os colegas e a comunidade, de forma contextualizada a sua realidade. Os resultados destas investigações começam a aparecer a partir de 2015 e assumem força em 2018 e 2019. Contudo, acreditamos que o advento da pandemia em 2020 impactou nas investigações em curso e, consequentemente, reduziu o quantitativo de publicações na área.

As 169 publicações selecionadas foram submetidas à categorização e obtivemos os resultados sumarizados na tabela 2 e que são discutidos na sequência.

Tabela 2 - Resultados encontrados em função dos critérios de análise.

\begin{tabular}{|l|l|c|c|}
\hline \multicolumn{2}{|c|}{ Critério de análise } & \multicolumn{1}{c|}{ Característica encontrada } & Qtd. \\
\hline \multirow{2}{*}{ Cenário de intervenção } & Ensino Médio & 50 & 29,5 \\
\cline { 2 - 4 } & Ensino Fundamental & 49 & 28,9 \\
\cline { 2 - 4 } & Não identificado & 33 & 19,5 \\
\hline
\end{tabular}

Recebido em: 24/05/2021

Aceite em: 22/09/2021 


\begin{tabular}{|c|c|c|c|}
\hline \multirow[t]{5}{*}{$\begin{array}{l}\text { Critério de análise } \\
\end{array}$} & Característica encontrada & Qtd. & $\%$ \\
\hline & Ensino superior & 25 & 14,7 \\
\hline & EJA & 02 & 1,18 \\
\hline & Educação infantil & 01 & 0,59 \\
\hline & Curso profissionalizante & 01 & 0,59 \\
\hline \multirow{2}{*}{ Tipos de Pesquisas } & Empírica & 141 & 83,4 \\
\hline & Teórica & 28 & 16,5 \\
\hline \multirow{11}{*}{ Estratégias Metodológicas } & Ensino por investigação & 91 & 53,8 \\
\hline & Resolução de problemas & 36 & 21,3 \\
\hline & Jogos & 5 & 2,95 \\
\hline & Sala de aula invertida & 4 & 2,36 \\
\hline & TICS & 4 & 2,36 \\
\hline & Peer instruction & 3 & 1,77 \\
\hline & Role playing games & 3 & 1,77 \\
\hline & Ensino por pesquisa & 1 & 0,59 \\
\hline & Ensino híbrido & 1 & 0,59 \\
\hline & Aprendizado baseado em evidências & 1 & 0,59 \\
\hline & Team based learning & 1 & 0,59 \\
\hline \multirow{14}{*}{$\begin{array}{c}\text { Benefícios da utilização de metodologias } \\
\text { ativas no ensino }\end{array}$} & Motivação & 70 & 41,4 \\
\hline & Autonomia & 69 & 40,8 \\
\hline & Rompimento com o ensino tradicional & 46 & 27,2 \\
\hline & Desenvolvimento do conhecimento científico & 36 & 21,3 \\
\hline & Desenvolvimento da argumentação & 35 & 20,7 \\
\hline & Estímulo do senso crítico & 33 & 19,5 \\
\hline & Relações entre conteúdo e cotidiano & 31 & 18,3 \\
\hline & $\begin{array}{l}\text { Desenvolvimento da habilidade do trabalho } \\
\text { em equipe }\end{array}$ & 28 & 16,5 \\
\hline & Familiarização com a linguagem científica & 24 & 14,2 \\
\hline & Formulação de hipóteses & 20 & 11,8 \\
\hline & Promoção de discussões & 7 & 4,14 \\
\hline & Interdisciplinaridade & 6 & 3,55 \\
\hline & Estímulo à criatividade & 2 & 1,18 \\
\hline & Não fragmentação de conteúdos & 1 & 0,59 \\
\hline \multirow{3}{*}{ Áreas disciplinares de Trabalho } & Ciências Naturais & 118 & 69,8 \\
\hline & Matemática e Ciências exatas & 1 & 0,59 \\
\hline & Não identificados & 50 & 29,5 \\
\hline $\begin{array}{c}\text { Metodologias ativas para formação de } \\
\text { professores }\end{array}$ & $\begin{array}{l}\text { Limites e possibilidades para a formação } \\
\text { docente }\end{array}$ & 11 & 6,50 \\
\hline Análise e avaliação de metodologias ativas & $\begin{array}{l}\text { Ferramentas e/ou categorias de análise e } \\
\text { avaliação }\end{array}$ & 4 & 2,30 \\
\hline
\end{tabular}

Fonte: elaborado pelos autores.

Os artigos analisados mostram que, os trabalhos com metodologias ativas são encontrados em diferentes cenários de intervenção: ensino fundamental (49) compreendem cerca de 28,9\% dos trabalhos; no ensino médio (50) 29,5\%; o ensino superior possui (25) $14,7 \%$ dos trabalhos; a educação infantil e cursos profissionalizantes possuem (1) $0,59 \%$ de trabalhos cada um, a educação de jovens e adultos (EJA) possui (2) 1,18\% dos trabalhos; e 19,5\% dos trabalhos, apesar de apresentarem a escola como cenário de intervenção não indicam o nível de escolaridade a que se destinam as propostas e práticas. 
Dentre os 169 estudos analisados, 141 são de natureza empírica, ou seja, 83,4 \% dos trabalhos utilizaram-se de abordagens de intervenção para suas investigações. No entanto, também identificamos outros tipos de pesquisas de natureza teórica, foram 28 artigos $16,5 \%$ - com estudos que fazem revisão de literatura, analisam livros didáticos, ou dedicam-se a outras discussões e investigações de cunho teórico. É importante destacarmos que dois artigos fazem análise de livros didáticos das disciplinas de Química e Biologia e buscam analisar e identificar a presença da metodologia da resolução de problemas e atividades investigativas nos livros didáticos. Já os demais estudos teóricos procuram discutir as contribuições do uso da investigação para o ensino.

Em um estudo de revisão de literatura realizada por Pastorio e Souza (2019), com o objetivo de compreender como as metodologias ativas estão surgindo no contexto da Educação em Ciências, os autores identificaram que aproximadamente $30 \%$ das publicações associadas ao desenvolvimento de metodologias ativas foram desenvolvidas no Ensino Médio, enquanto outros $30 \%$ são desenvolvidas no Ensino Superior. Acerca do Ensino Fundamental, os dados são semelhantes ao presente estudo, 29,5\%. No entanto, encontramos $14,7 \%$ dos estudos direcionado ao Ensino Superior, frente à 28,8\% desenvolvidos no Ensino Fundamental, o que demonstra o interesse em investigar o impacto destas metodologias o mais cedo possível, no percurso da Educação em Ciência escolar da Educação Básica, a exemplo de um trabalho que se destina já à Educação Infantil. Já Pereira et al. (2019) também identificam esta tendência, pois encontraram, na maioria das investigações, objetivos de avaliação de atividades práticas e sequências didáticas desenvolvidas no Ensino Fundamental, na disciplina de Ciências.

Ao analisar as estratégias metodológicas, encontramos a utilização de metodologias ativas variadas: o ensino por investigação, jogos, sala de aula invertida, experimentação, resolução de problemas, ensino por pesquisa, peer instruction, ensino híbrido, aprendizagem baseada em casos, evidências, equipes e projetos, dentre outras. É interessante notar que no Ensino de Ciências a maior parte dos trabalhos (91) são referentes à metodologia do ensino por investigação, correspondendo a 53,8\% dos trabalhos, seguido pela metodologia da resolução de problemas (36) representado por 21,3\% dos trabalhos publicados. Estas são metodologias que têm como princípio o fazer científico, de essencial compreensão para alfabetização científica (FOUREZ, et al., 1997). 
Estas metodologias, que se fundamentam em estratégias do fazer científico, exploram a observação, o questionamento, o levantamento de hipóteses e a experimentação, o que pode contribuir para um melhor resultado em aulas de ciências, afirmação corroborada pelos resultados apresentados por Souza e Silva (2019). Estes autores relatam uma mudança no conhecimento de senso comum, para um perfil de conhecimentos mais científicos em alunos que desenvolveram metodologias investigativas pautadas pela resolução de problemas. Silva, Malheiro e Teixeira (2015) também apresentam em seus resultados que o conhecimento das etapas do trabalho científico desenvolvido na metodologia de aprendizagem baseada em problemas (ABP), contribuiu para que os alunos compreendessem a necessidade de analisar as evidências que lhes são apresentadas e buscar conhecimentos que contribuam com a solução do problema proposto.

Outras metodologias apresentaram um número expressivamente menor em relação às duas citadas anteriormente. A sala de aula invertida e TICs possuem quatro trabalhos cada, o que corresponde à 2,36\% dos trabalhos analisados. Peer instruction e a metodologia Role playing games possuem três trabalhos, o que representa 1,77\%; metodologias que utilizam jogos para o ensino possuem 5 trabalhos, correspondendo a 2,95\%; as metodologias de ensino por pesquisa, ensino híbrido, aprendizado baseado em evidências e Team based learning possuem apenas 1 estudo em cada uma das metodologias, o que representa um valor de $0,59 \%$ de estudos, demonstrando menor interesse em investigações na área de Ensino de Ciências.

Estudos de revisão de literatura como os de Pastorio e Souza (2019), Pereira et al. (2019), Oliveira e Jardim (2019) identificaram dados semelhantes aos nossos, visto que apontam a raridade de trabalhos investigando a utilização de metodologias ativas em jogos, ou gamificação no Ensino de Ciências, bem como a baixa adesão ao uso de TICs. Ambos os estudos apontam que metodologias assemelhadas às metodologias de pesquisa científica são preferência entre os pesquisadores da área.

Ao analisarmos a categoria benefícios da utilização de metodologias ativas no ensino, pontuamos os seguintes benefícios que foram evidenciados nos estudos: motivação do aluno $(41,4 \%)$, rompimento com o ensino tradicional $(27,2 \%)$, desenvolvimento do conhecimento científico $(21,3 \%)$, desenvolvimento da capacidade de argumentação (20,7\%), estímulo ao senso crítico (19,5\%), relação entre conteúdos escolares e cotidiano (18,3\%), desenvolvimento da capacidade de trabalhar em equipe (16,5\%), familiarização com a linguagem científica $(14,2 \%)$, formulação de hipóteses $(11,8 \%)$, incentivo às discussões 
$(4,1 \%)$, interdisciplinaridade $(3,5 \%)$, estímulo à criatividade $(1,1 \%)$. Além disso, identificamos menções ao desenvolvimento de autonomia no aluno e a redução da fragmentação do ensino. Todos os trabalhos apresentam intersecções entre os benefícios, ou seja, é possível identificar mais de um benefício em cada trabalho.

É importante destacarmos que a motivação do aluno para a aprendizagem é apontada em $41,4 \%$ dos trabalhos. Fato este evidenciado devido às metodologias ativas favorecerem a busca pelo conhecimento, assim, o aluno não obtém todas as respostas como ocorreria em uma aula tradicional, na qual o professor se encarrega de sanar qualquer dúvida que possa surgir. Ao utilizar as metodologias ativas, a dúvida, os questionamentos e os problemas propostos mantêm o aluno engajado a buscar respostas e soluções através de meios variados. Acreditamos que o uso de metodologias ativas também impede a monotonia, fator que contribui para desmotivar os alunos (GARCIA STOLL, et al., 2020). Lima e Valentim (2015) afirmam que quando os alunos são colocados frente a uma nova forma de aprender, em que são agentes ativos da sua aprendizagem, o resultado obtido são alunos motivados e estimulados a continuar buscando novos conhecimentos, consequentemente melhorando a aprendizagem.

Da mesma forma, Almeida, Valadares e Junior (2015) apresentam resultados que demonstram um maior interesse dos alunos em aulas que fogem do modelo tradicional, promovendo maior diálogo e discussão sobre os conteúdos trabalhados. São motivos pelos quais, o rompimento com o ensino tradicional aparece como o segundo benefício mais citado pelos estudos, aparecendo em $27,2 \%$ dos trabalhos.

Consideramos que a superação de modelos transmissivos de informações e o desenvolvimento da autonomia do aluno é o eixo central das metodologias ativas, uma vez que o aluno é colocado como foco da aprendizagem e precisa aprender a desenvolver suas próprias maneiras de alcançar o objetivo proposto pela metodologia. No entanto, Prado e Giannella (2019), apesar de destacarem o desenvolvimento da autonomia do aluno e de seu protagonismo no processo de aprendizagem, alertam para a necessidade e importância do professor como mediador e condutor dos processos de ensino.

Em relação às áreas disciplinares dos trabalhos foram identificados 118 trabalhos cujo foco de estudo é na área de Ciências Naturais (Ciências, Biologia, Física e Química), o que corresponde a 69,82\%. Apenas um trabalho, ou 0,59\%, teve como foco a Matemática, 
pertencente às Ciências Exatas. Outros 50 estudos não se dedicaram a estudar as metodologias ativas em áreas disciplinares ou áreas do conhecimento, tratava-se de reflexões de cunho mais teórico, nos quais enquadram-se, por exemplo, as revisões bibliográficas, ensaios teóricos, construção de ferramentas de avaliação, dentre outros.

Dentre os 118 estudos classificados na área das Ciências Naturais, 43 trabalhos $(25,4 \%)$ tiveram como foco o Ensino de Biologia. Nestes estudos identificamos seis diferentes metodologias ativas utilizadas: ensino por investigação, resolução de problemas, role playing game, experimentação, jogos e a sala de aula invertida. Consideramos baixa a diversidade de metodologias analisadas para o Ensino de Biologia, especialmente quando o presente estudo identificou uma grande variedade de metodologias. No entanto, ao olharmos para estes 43 trabalhos a situação fica ainda mais reduzida, pois 28 trabalhos investigam a metodologia de ensino por investigação e 11 são estudos relacionados à resolução de problemas. Ou seja, duas metodologias correspondem a mais de $90 \%$ das investigações que utilizam metodologias ativas no Ensino de Biologia.

Os dados demonstram que as outras metodologias ativas são preteridas no Ensino de Biologia, onde destacam-se apenas o ensino por investigação e a resolução de problemas, provavelmente pelos motivos que já mencionamos acima, visto que estas metodologias se assemelharem com as etapas do fazer científico. Assim, consideramos que este campo de estudos e prática é carente de investigações que analisem outras estratégias. Não queremos aqui depreciar as duas metodologias priorizadas, pelo contrário, elas são metodologias importantes e interessantes. Inclusive destacamos o estudo de Murata e Oliveira (2017) que, ao analisarem livros didáticos de Biologia, encontraram grande quantidade de atividades com uma proposta problematizadora que pode desenvolver no aluno um senso investigativo e crítico ao construir suas respostas em busca da resolução de problemas.

Além disso, essas metodologias foram utilizadas como estratégias para a formação de professores de Biologia, como nos estudos de Wanzeler, Tavares e Malheiro (2015). Nos dois estudos os pesquisadores concluem afirmando que as metodologias ativas de ensino por investigação e resolução de problemas, também chamada de aprendizagem baseada em problemas, ainda são pouco conhecidas e utilizadas por professores e na formação de professores. Os autores defendem que as metodologias são responsáveis por promover uma evolução do conhecimento prévio dos participantes e o desenvolvimento da capacidade de raciocínio. Os dois estudos demonstram que, apesar da dificuldade inicial, os professores, 
após vivenciarem a metodologia, sentiram-se motivados a utilizá-las em suas aulas na Educação Básica.

Por fim, identificamos 11 trabalhos que utilizaram metodologias ativas para a formação de professores, correspondendo à $6,50 \%$ do total. Todos estes estudos estão dedicados a compreender limites e possibilidades e propor estratégias para a formação de professores. No entanto, como mencionamos no parágrafo anterior, apenas dois ocuparam-se da formação de professores de Biologia. Outros quatro trabalhos $(2,3 \%)$ são investigações que se ocuparam de construir, propor e avaliar ferramentas para análise de metodologias ativas. No entanto, nenhuma delas destina-se ao Ensino de Biologia especificamente, demonstrando a raridade de estudos destinados ao Ensino de Biologia e configurando-se como um campo de investigação a ser explorado.

\section{CONSIDERAÇÕES FINAIS}

Esta revisão sistemática analisou trabalhos acadêmicos referentes às metodologias ativas levando em consideração diferentes abordagens, contextos e áreas de trabalho. Acerca das estratégias utilizadas nestes estudos, é possível perceber uma predominância do ensino por investigação e resolução de problemas no Ensino de Ciências. Foi possível identificar que grande parte dos estudos foram desenvolvidos em turmas do ensino médio, seguido pelo ensino fundamental e com poucos trabalhos realizados no ensino superior e na formação de professores. Neste sentido, são necessárias reflexões e novos estudos acerca das metodologias utilizadas para a formação superior, especialmente na formação de professores, visto que as vivências da formação inicial são cruciais para a construção de saberes que possibilitem aos docentes o desenvolvimento de novas estratégias no contexto escolar.

Em complementação, é preciso destacar a carência de estudos relacionados à formação de professores da área de Ciências e Biologia, especialmente no que se refere às metodologias ativas, bem como a pouca quantidade de trabalhos dedicados a outras metodologias que não sejam a Problematização e a Investigação, quando referimo-nos ao Ensino de Biologia. Sendo assim, existe uma lacuna referente ao assunto na área, necessitando que mais estudos sobre outras metodologias ativas sejam realizadas ou potencialmente significativas para a formação docente. Acreditamos que também são necessárias mais pesquisas referentes às metodologias na formação de professores, de modo a compreender as necessidades formativas para que os 
docentes se sintam preparados para implementá-las em sala de aula, superando modelos tradicionais de ensino.

Em relação aos benefícios e possibilidades, os estudos evidenciam e sugerem que as metodologias ativas têm grande potencial para romper com o ensino tradicional-transmissivo, favorecendo o desenvolvimento da autonomia do aluno (BORSEKOWSKY et al., 2021). Desta forma, as metodologias ativas podem favorecer o desenvolvimento de habilidades de reflexão, pensamento crítico e investigativo nos educandos e assim desvinculando o ensino de estratégias bancárias e acríticas, pautadas pela repetição e memorização. Os estudos apontam que as metodologias ativas podem potencializar a formação de sujeitos críticos, autônomos e motivados.

Além disso, consideramos que as metodologias ativas estão articuladas com as novas propostas curriculares da Educação Básica brasileira. São metodológicas alinhadas à Base Nacional Comum Curricular (BNCC) que, apesar das críticas, têm como foco o protagonismo e a autonomia dos alunos. A BNCC possui, dentre as competências a serem desenvolvidas pelo Ensino de Ciências, o desenvolvimento de abordagens próprias para a compreensão das ciências, incluindo a "investigação, a reflexão, a análise crítica, a imaginação e a criatividade, para investigar causas, elaborar e testar hipóteses, formular e resolver problemas e criar soluções" (BRASIL, 2018, p. 09). Características como àquelas evidenciadas neste estudo, inclusive como benefícios das estratégias.

No que diz respeito aos desafios e necessidades, é necessário um olhar crítico para as metodologias ativas, seu potencial pedagógico e didático é inegável, no entanto, como afirmam Valério e Moreira (2018, p.226)

Resultados alvissareiros se acumulam, repercutem entre a comunidade de educadores e induzem políticas públicas e institucionais. Questionamentos pedagógicos, sociológicos, metodológicos e empíricos, no entanto, também existem, formalizados e documentados, e não podem ser negligenciados ou escamoteados.

Portanto, são necessárias reflexões, discussões e análises acerca das necessidades para o desenvolvimento de metodologias ativas na Educação Básica. Destacamos a necessidade prioritária de formação docente. Consideramos urgente a necessidade de cursos de formação continuada aos professores e a inclusão do debate crítico na formação inicial. Apenas com formação será possível a construção de novos conhecimentos profissionais que permitam aos 
docentes romper com antigas práticas educativas, buscando a flexibilização, a pluralidade e a inovação, elementos demandados da educação na atualidade (FÜHR, 2019). No contexto atual, em meio a uma pandemia, acreditamos que são necessárias estratégias inovadoras que articulem teorias e tecnologias de forma mais dinâmica. Neste sentido, concordamos com Venturi e Lisbôa $(2021$, p. 22) ao afirmarem que a formação de professores tem como desafio proporcionar

[...] o desenvolvimento da criatividade e da capacidade de resolução de problemas, competências de grande importância numa sociedade de céleres mudanças. No contexto atual, ser professor requer reinventar-se. Não basta somente ter domínio do conteúdo a ser ensinado, é imprescindível que a formação possibilite o desenvolvimento de conhecimentos pedagógicos e tecnológicos.

Além disso, em vista da diversidade de metodologias ativas, outro desafio será propor novos estudos que permitam discutir possibilidades de formação docente, prática e reelaborações que se adequem às teorias e às práticas dos professores nas realidades e contexto das escolas brasileiras, sejam na realidade presencial, remota, híbrida, pandêmica ou não pandêmica.

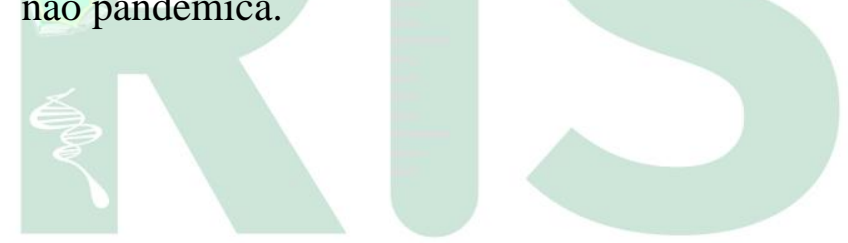

\section{REFERENCIAS:}

ALMEIDA, T.D.Q; VALADARES, J.M; JUNIOR, O.A. Uso de demonstrações investigativas em sala de aula de física para promover o engajamento dos estudantes. Atas do X Encontro Nacional de Pesquisa em Educação em Ciências (X ENPEC), Águas De Lindóia: São Paulo, 2015.

BATES, T. Educar na era digital: design, ensino e aprendizagem. Trad. Mattar, J. 1. ed. São Paulo: Artesanato Educacional, 2017.

BERBEL, N. A. N. As metodologias ativas e a promoção da autonomia de estudantes. Semina: Ciências Sociais e Humanas, v. 32, n. 1, p. 25-40, 2011.

BORGES, T.S; ALENCAR, G. Metodologias ativas na promoção da formação crítica do estudante: o uso das metodologias ativas como recurso didático na formação crítica do estudante do ensino superior. Cairu em Revista. Ano 3, n. 4, jul/ago., 2014.

BOROCHOVICIUS, E; TORTELLA, J.C.B. Aprendizagem Baseada em Problemas: um método de ensino-aprendizagem e suas práticas educativas. Ensaio: Avaliação e Políticas Públicas em Educação: Rio de Janeiro, v. 22, n. 83, p. 263-294, abr/jun., 2014. 
BORSEKOWSKY, A.; et al. Aprendizagem significativa: transformando a sala de aula em laboratório para o ensino de ciências. Revista Insignare Scientia - RIS, v. 4, n. 2, p. 13-22, 5 fev. 2021.

BOTO, C. António Nóvoa: uma vida para a educação. Educação e Pesquisa (USP): São Paulo, v. 44, e201844002003, 2018.

BRASIL. Ministério da Educação. Base Nacional Comum Curricular. Brasília, 2018.

COSENZA, R. M.; GUERRA, L. Neurociência e educação: como o cérebro aprende. Porto Alegre: Artmed, 2011.

FOUREZ, G. et al. Alfabetización científica y técnica. Argentina: Ediciones Colihue, 1997.

FÜHR, R.C. Educação 4.0 e seus Impactos no Século XXI. Atas do V Congresso Nacional de Educação - CONEDU: Fortaleza - CE, 2019.

FURLANI, C; OLIVEIRA, T.B. O ensino de ciências e biologia e as metodologias ativas: o que a BNCC apresenta nesse contexto?. Simpósio Internacional de Linguagens Educativas. Bauru. 2018.

GARCIA STOLL, V.; et al. A Experimentação no Ensino de Ciências: um Estudo no Catálogo de Teses e Dissertações da CAPES. Revista Insignare Scientia - RIS, v. 3, n. 2, p. 292-310, 25 ago. 2020.

GIL, A.C. Como elaborar projetos de pesquisa. São Paulo: Atlas, 2002.

KRASILCHIK, M; MARANDINO, M. Ensino de ciências e cidadania. São Paulo: Moderna, 2004.

LIMA, D.B; SCHROEDER, J.S; VALENTIM, L.M. Uma investigação sobre a Aprendizagem Baseada em Problemas nas Ciências da Natureza: percepções de um grupo de estudantes do Ensino Médio. Atas do X Encontro Nacional de Pesquisa em Educação em Ciências (X ENPEC), Águas de Lindóia: São Paulo, 2015.

MATTAR, J. Metodologias ativas para a educação presencial, blended e a distância. São Paulo: Artesanato Educacional, 2017.

MORÁN, J. Metodologias ativas e modelos híbridos na educação. In: YAEGASHI, S e outros (Orgs). Novas Tecnologias Digitais: Reflexões sobre mediação, aprendizagem e desenvolvimento. Curitiba: CRV, 2017.

MOTA, A.R; ROSA, C.T.W. Ensaio sobre metodologias ativas: reflexões e propostas. Espaço Pedagógico: Passo Fundo, v. 25, n. 2, 2018.

MOURA, B.L; SANTOS, C.A.M; JOSÉ, M.A.M. Aplicação do Peer Instruction no ensino de matemática e ciências exatas para alunos de quinto ano do ensino fundamental. Atas do $\mathbf{X}$ Encontro Nacional de Pesquisa em Educação em Ciências (X ENPEC), Águas de Lindóia: São Paulo, 2015.

Recebido em: 24/05/2021

Aceite em: 22/09/2021 
MURATA, N.G; OLIVEIRA, A.L. Identificação e análise de Atividades Investigativas em Livros Didáticos de Biologia. Atas do XI Encontro Nacional de Pesquisa em Educação em Ciências (XI ENPEC), Florianópolis: Santa Catarina, 2017.

NUNES, S.L.A; COUTINHO, F.A; MORAES, G.S.P. Neurociências e educação em ciências. Memória e ensino. Atas do X Encontro Nacional de Pesquisa em Educação em Ciências (X ENPEC), Águas de Lindóia: São Paulo, 2015.

OLIVEIRA; F.S; JARDIM, M.I.A. Metodologias para o uso de tecnologias de informação e da comunicação no ensino de ciências: uma revisão sistemática. Atas do XII Encontro Nacional de Pesquisa em Educação em Ciências (XII ENPEC) Natal: Rio Grande do Norte, 2019.

PAIVA, M.R.R; et al. Metodologias ativas de ensino-aprendizagem: revisão integrativa. Revista Sanare: Sobral, v. 15, n. 02, p. 145- 153, 2016.

PASTORIO, D.P; SOUZA, L.A.V.D. As metodologias ativas nas pesquisas de ensino: uma revisão de literatura no ENPEC. Atas do XII Encontro Nacional de Pesquisa em Educação em Ciências (XII ENPEC), Natal: Rio Grande do Norte, 2019.

PEREIRA, G.W; et al. Role- Playing Games no Ensino de Ciências: uma revisão de literatura. Atas do XII Encontro Nacional de Pesquisa em Educação em Ciências (XII ENPEC), Natal: Rio Grande do Norte, 2019.

PRADO, R.T; GIANELLA, T.R. Ensino por investigação: Uma revisão de literatura sobre os trabalhos apresentados nos Encontros Nacionais de Pesquisa em Educação em Ciências. Atas do XII Encontro Nacional de Pesquisa em Educação em Ciências (XII ENPEC), Natal: Rio Grande do Norte, 2019.

RICHARDSON, R. J. Pesquisa social: métodos e técnicas. São Paulo: Atlas, 1999.

SILVA, A.A.B; MALHEIRO, J.M.S; TEIXEIRA, O.P.B. Curso de férias "Experimentando Ciências", evidências da Formação do Espírito Científico. Atas do X Encontro Nacional de Pesquisa em Educação em Ciências (X ENPEC), Águas de Lindóia: São Paulo, 2015.

SOUZA, S.S; SILVA, E.L. Atividades Investigativas e Abordagem Contextual no Ensino de Ciências: uma intervenção didática do PIBID. Atas do XII Encontro Nacional de Pesquisa em Educação em Ciências (XII ENPEC), Natal: Rio Grande do Norte, 2019.

VALÉRIO, M; MOREIRA, A.L.O.R. Sete Críticas à Sala de Aula Investida. Revista Contexto \& Educação. Unijuí: ano 33, nº 106, set-dez, 2018.

VENTURI, T; LISBÔA, E. S. Estágio Em Tempos de Pandemia: mudanças de paradigma na concepção e operacionalização no ensino superior. Revista Cenas Educacionais: Caetité BA, v.4, n.10746, p.1-25, 2021.

WANZELER, D.R; TAVARES, E.C; MALHEIRO, J.M.S. Concepções de aprendizagem baseada em problemas (ABP) manifestados por professores de ciências participantes de um

Recebido em: 24/05/2021

Aceite em: 22/09/2021 
curso de férias. Atas do X Encontro Nacional de Pesquisa em Educação em Ciências (X ENPEC), Águas de Lindóia: São Paulo, 2015.

ZÔMPERO, A.F; LABURÚ, C.E. Atividades investigativas no ensino de ciências: aspectos históricos e diferentes abordagens. Revista Ensaio Pesquisa em Educação em Ciências: Belo Horizonte, v. 13, n. 3, set-dez, 2011. 